\title{
TCOM \\ Understanding the relationship between sharing personal anecdotes, warmth, curiosity, risk perception and mitigation in communicating the threat of climate change
}

\section{Reyhaneh Maktoufi}

\begin{abstract}
While most Americans believes in climate change, to elicit action, communicators should use strategies to convey risks. One strategy is to cognitively engage individuals by eliciting curiosity. Previous studies have shown that individuals with higher science curiosity are more likely to perceive the risk of climate change. This study uses scientists' act of sharing personal anecdotes to elicit curiosity and examines the effect of scientist's traits on risk perception. Results show that anecdotes do not affect any of the variables. However, there is a positive relationship between curiosity and risk perception, and between trust in scientists and risk perception.
\end{abstract}

Keywords

DOI

Environmental communication; Public perception of science and technology; Science communication: theory and models; Popularization of science and technology; Public engagement with science and technology; Risk communication

https://doi.org/10.22323/2.20070208

Submitted: 30th April 2021

Accepted: 1st November 2021

Published: 13th December 2021

Introduction

The 2020 Yale Climate Opinion map of the US shows that $64 \%$ of Americans rarely or never discuss global warming. Seventy-four percent of Americans hear about global warming once a week or less, and only $43 \%$ perceive that global warming will at least moderately affect them. This report highlights the lack of public curiosity and dialogue in the scientific discussion, hindering the public's participation in the scientific discourse. This data also shows the fairly low perception of risk of climate change [Marlon et al., 2020].

Scientific communities such as the National Academies of Sciences, Engineering and Medicine [2017] advocate a move towards citizen-centered strategies to improve the status of science outreach. However, little research has examined how the public's curiosity in science might impact outreach and dialogues around more controversial topics such as climate change. In this study, I examine how scientists 
can elicit curiosity and if curiosity can increase climate change risk perception and mitigation. Throughout this experimental design, I also investigate the role of political partisanship and education on risk perception and mitigation. In addition, I examine how the scientists' perceived warmth, competence, and trustworthiness affect the participants' curiosity and risk perception/mitigation.

I suggest the study of curiosity in science communication for two main reasons. First, eliciting public curiosity assumes a more active role for the public and changes the expert-centered narrative to one that focuses on the public's questions, needs, and opinions. Second, studies, including Kahan et al. [2017] and Sjöberg [2007], show the effect of curiosity on risk perception and risk mitigation. Risk perception is associated with an individual's views on risk rather than objective risk [Renn and Rohrmann, 2000]. Risk mitigation includes activities one engages in to mitigate that risk. As researchers seek to develop models explaining the factors contributing to risk perception, curiosity seems to have a significant role in risk perception and mitigation.

One approach to elicit curiosity is the use of personal anecdotes in communication. Some studies [e.g., Goldstein and Benassi, 1994; Mazer, Murphy and Simonds, 2007] suggest that using personal anecdotes in the classroom improves classroom participation and students asking questions. However, these results are mostly based on surveys and not other measurement strategies [Wambach and Brothen, 1997]. In this study, I examined the relationship between the use of personal anecdotes and curiosity through an experiment to establish causality. Moreover, I examine curiosity behavior, not just intent.

I discuss factors that mediate the effect of personal anecdotes on curiosity. Some studies in the learning sciences show that personal anecdotes can elicit the perception of speaker warmth. Others show that a speaker's perceived warmth evokes higher curiosity. Based on these studies and those on the use of personal anecdotes, I suggest that a speaker's perceived warmth mediates the effect of personal anecdotes on curiosity.

Curiosity is a tool with different potentials ranging from a motivation to find answers to a way to engage the public in a conversation around science through inquiry. Kashdan et al. [2018] define curiosity "as the recognition, pursuit, and desire to explore novel, uncertain, complex, and ambiguous events" (p. 130). Thus, curiosity is a result of a cognitive gap and manifested as a desire or behavior. These desires and actions include "openness to experience, novelty seeking, need for cognition, intrinsic motivation, tolerance of ambiguity, tolerance for uncertainty, frustration tolerance, and sensation seeking" (p. 130). This definition integrates definitions that relate to curiosity as a feeling and behavior in addition to previous definitions of curiosity as an impulse, cognitive gaps, a feeling etc. [Hunt, 1965; James, 1983; Kang et al., 2009; Loewenstein, 1994]

Curiosity has shown to improve learning outcomes and long-term memory [Jepma et al., 2012; Kang et al., 2009] encourage individuals to dedicate resources and time to find answers [Kang et al., 2009] and motivate them to engage in exploratory 
behavior [Arnone et al., 2011]. These outcomes are particularly important in the field of science communication that seeks to promote public engagement through dialogues about science [National Academies of Sciences, Engineering and Medicine, 2017].

In this study, I focus on curiosity as a tool for dialogue and engagement. Expressed curiosity in the form of inquiry [Getahun, Aulls and Saroyan, 2014] can lead to a conversation between a curious public and a responsive expert. Due to the nature of curiosity as a latent variable [Kahan, 2016], different phenomena can reflect curiosity, such as the time one spends exploring an object or asking questions. Thus, in this study, I have chosen Kashdan et al. [2018] definition of curiosity, encompassing various exploratory behaviors and desires. Also, when examining the literature, I include topics that fall into the definition of curiosity, but are not referred to explicitly as curiosity in the original studies. The main topics I will be examining include engagement, dialogues, questions, participation, and conversations. However, when operationalizing curiosity as a variable in the study design, I refer to the behavior of asking questions, as curiosity.

As for other terms, I refer to conversations, as engagement between the expert and the audience. In addition, when studies examine participants asking questions, I referred to the action as "dialogue" even if the studies refer to them otherwise. I will still refer to the goal of the study as eliciting curiosity.

\section{Curiosity, personal anecdotes, and warmth perception}

Scholars have suggested multiple ways to elicit curiosity. Examples include offering novel and complex information, expressing the importance of a piece of information, or announcing a surprising piece of information [Golman et al., 2012; Loewenstein, 1994; Silvia, 2008]. However, one strategy that I argue has the potential to elicit curiosity is disclosing personal anecdotes.

Some studies refer to the term interpersonal self-disclosure to describe the sharing of personal stories and anecdotes. Wheeless and Grotz [1976] define this term as "any message about the self that a person communicates to another" (p. 47). Although most studies show the positive effect of self-disclosure on students' expression of curiosity, I suggest the methods used in these studies leave room for a causal investigation of this relationship.

Most studies that show a positive effect have one important point in common; they use interest and reports of participation for evaluation. Goldstein and Benassi [1994] show that students report being more willing to participate in class when teachers engage in more self-disclosure. Goldstein and Benassi use a survey that examine both the student and teacher's perception of the teacher's self-disclosure and the student's participation, including willingness to ask more questions. These results are in line with Cayanus, Martin, and Goodboy's findings [2009] that with the teacher's relevant self-disclosure, the students were more motivated to participate in class dialogues and are more likely to ask questions.

These studies, however, have limitations that can result in outcomes that counter one another. Wambach and Brothen [1997] claim that the previously mentioned 
study may contain biases related to participation in surveys. Besides, the self-report measure that discuss perception of participation rather than observing the behavior, might not be an accurate representation of participation in a dialogue in the classroom. In Wambach and Brothen's study, eight students observed 22 randomly chosen college classroom sessions. Each session was monitored by two students who would record if participation existed or not in 5-minute intervals. They found that the teacher's self-disclosure did not significantly affect students' participation in the classroom, including how often they ask questions. An essential difference between the studies showing the positive effect of self-disclosure on participation in classroom dialogue, and Wambach and Brothen's study [1997], showing no such relationship, is their methods. Thus, Wambach and Brothen's research may suggest that disclosure only affects perception of classroom participation rather than participation behavior.

From these studies, there are two points to consider. First, due to their design as measuring observations or surveys of classroom participants, the findings demonstrate a correlation between self-disclosure and participation in the classroom (including inquiries) but no causation. An experimental design can contribute to the understanding of self-disclosure and the use of personal anecdotes as a factor that causes curiosity. Second, most studies that show the positive relationship between self-disclosure and dialogue rely on student self-reported perception of participation and not behavior.

In sum, studies suggest that self-disclosure is related to curiosity. However, they are unable to establish causation. In this study, I use an experimental design to establish causality while focusing on curiosity. When referring to greater curiosity here, it refers to larger number of questions asked by the audience. I suggest the following hypothesis (Figure 1):

H1: Scientists who engage in higher levels of self-disclosure will induce greater curiosity than scientists who engage in lower levels of self-disclosure.

For science communicators to elicit the audience's curiosity and engage them in a dialogue, it would be of great help to know if self-disclosure can elicit curiosity. Understanding what mediates the effect of self-disclosure can improve researchers and communicators' understanding of the mechanisms behind eliciting curiosity. This can provide an opportunity to use other strategies to elicit curiosity. In this section, I discuss one possible mediating factor: warmth.

Warmth has been defined in different ways by scholars, mostly emphasizing on a range of characteristics such as trustworthiness and kindness [Aaker, Vohs and Mogilner, 2010; Cuddy, Glick and Beninger, 2011], other-profitable [Peeters, 1995; as cited in Fiske, Cuddy et al., 2018], friendliness and empathy [Cuddy, Glick and Beninger, 2011], generosity, honesty, sincerity, helpfulness, and thoughtfulness [Aaker, Vohs and Mogilner, 2010]. Fiske, Xu et al. [1999] use warmth and likability interchangeably. In this review, I treat studies that evaluate likability as studies that assess an element of warmth.

Different studies have suggested various strategies to improve the perception of the source's warmth, friendliness, and benevolence. For example, studies suggest 


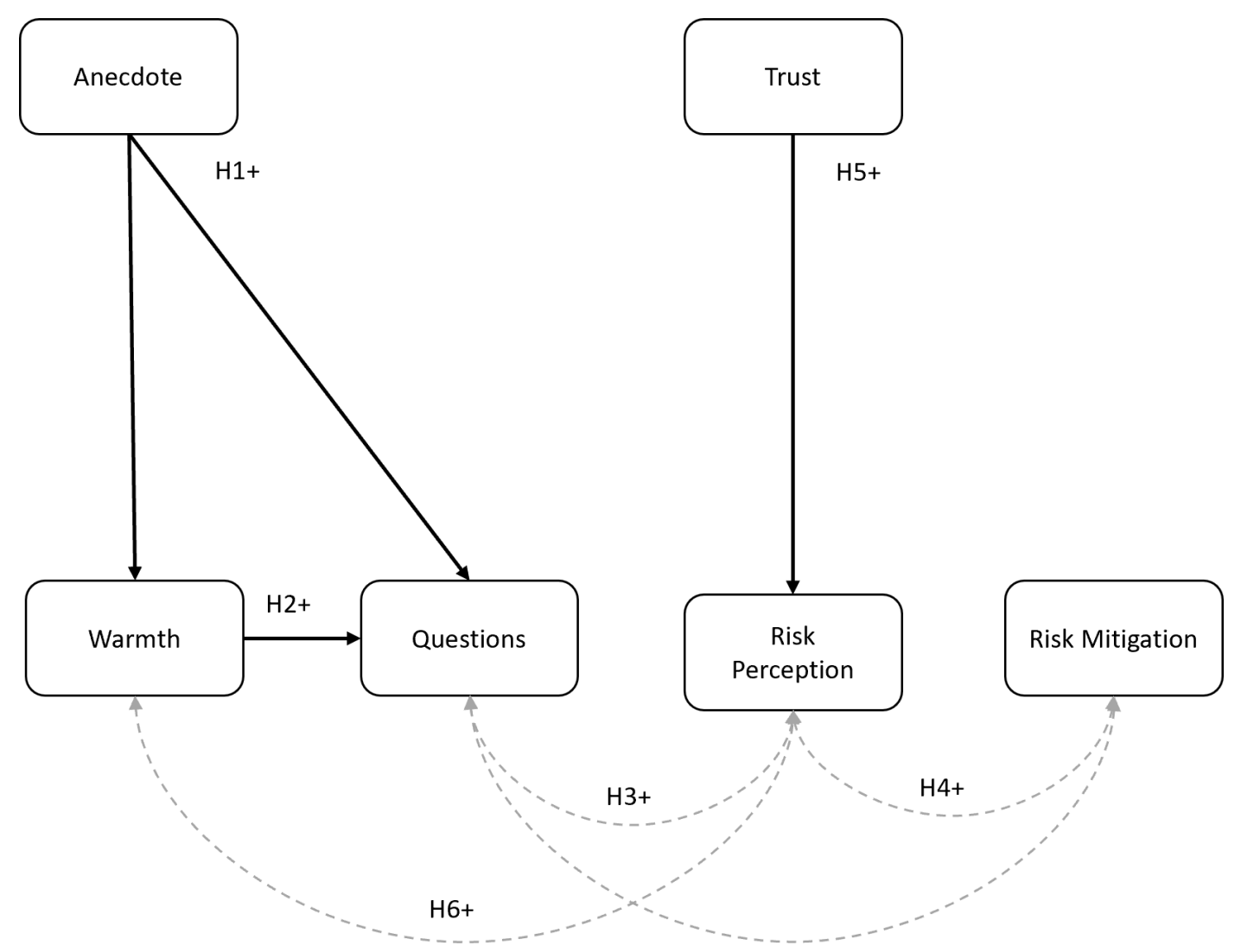

Figure 1. Suggested model for a Structural Equation Modeling analysis (trust: trust in scientist's reliability). NOTE: dashed lines represent correlational relationships.

helpfulness and caring to build warmth [e.g., Aaker, Vohs and Mogilner, 2010; Peloza and Hassay, 2006; Voelkl, 1995]. Others, including Moreland and Zajonc [1982], use familiarity to elicit likability and warmth. In a recent study Zahry and Besley [2021] show the effect of prosocial behavior and emotional appeals in eliciting warmth. Other strategies include showing one's family and friends [Aaker, Stayman and Hagerty, 1986], facial expressions such as smiling [Landrum, Mills and Johnston, 2013; Gheorghiu, Callan and Skylark, 2017], the use of first names to avoid attempting to assert superiority [Lakoff, 1977].

However, in this study the primary strategy I focus on is the use of a personal anecdote. Several studies describe how self-disclosure and the use of personal stories affect speaker's perception of warmth. A study by Sorensen [1989] shows that teachers' self-disclosure leads to more affective learning in students, including more liking of class and the teacher. This result is in line with a meta-analysis by Collins and Miller [1994], concluding that self-disclosure leads to more liking of the speaker. However, this strategy can have different effects depending on the intensity of its use, i.e., Cozby [1972] shows that although a medium amount of self-disclosure can help with the speaker's likability, the disclosure of highly intimate information or very low level of disclosure can reduce their likability. There is also a positive relationship between self-disclosure and connection with the speaker [Abrahamson, 2005; Altman and Taylor, 1973] and more empathy with them [Abrahamson, 2005]. These indicators of warmth show that self-disclosure can improve one's perception of warmth and likability. 
The second part of this section is regarding the effect of speaker's warmth on the expression of curiosity and engagement. Studies of classroom participation and engagement have found a positive correlation between warmth and student engagement [Hamre and Pianta, 2001; Hughes et al., 2008; Skinner and Belmont, 1993; Skinner, Wellborn and Connell, 1990; Voelkl, 1995]. Engagement in the context of these classroom studies is based on emotional and behavioral factors. For example, when students concentrate on the material and make intense efforts to implement learning material, they are considered engaged. Other activities showing engagement include showing enthusiasm, interest, and curiosity [Fredricks, Blumenfeld and Paris, 2004; Hughes et al., 2008; Skinner, Wellborn and Connell, 1990]. Researchers mainly assessed these variables based on the teacher's report of student's listening, study habits, compliance, cooperation, and participation [e.g., Hamre and Pianta, 2001]. Epstein [1981] shows that warmth motivates students to pay more attention in class and be more interested in the material, thus improving participation and leading to student success.

Based on the evidence I presented in this section, I suggest examining if warmth mediates the effect of personal anecdotes on curiosity (Figure 1). As personal anecdotes correlate with warmth perception and engagement, including inquiring from speaker, and warmth correlates with participation in classroom and inquiring from the speaker, warmth may be the path between personal anecdotes and curiosity. Considering the evidence I suggest examining if warmth mediates the effect of disclosing personal anecdotes on curiosity (Figure 1), leading to the following hypothesis:

H2: Scientists who are perceived as warmer, will elicit more questions than scientists who are perceived as less warm.

\section{Curiosity and risk perception/mitigation}

One of the variables connected to curiosity is risk perception. Risk perception refers to people's views on risk and is usually as a counterpart to "real" or "actual" risk [Renn and Rohrmann, 2000]. The understanding of what determines risk perception is a complex matter and many researchers have contributed to the literature by focusing on a range of factors from individual-level factors [eg Sjöberg, 2000] to cultural ones [e.g., Douglas and Wildavsky, 1983].

Renn and Rohrmann [2000] describe an integrative model of risk perception encompassing many factors such as heuristics of information processing, cognitive-affective factors, cultural backgrounds, and social-political institutions but not focusing on curiosity as an important variable affecting risk perception. A study by Kahan et al. [2017] shows how individuals with higher science curiosity, measured as a desire to consume more science-related content, were more likely to look for counter-attitudinal information, in this case, information about global warming. They were also more likely to perceive higher risk regarding global-warming regardless of their political partisanship. This finding hints at the possible effects of curiosity on societal risk perception and calls for a more in-depth examination of this relationship.

The latest Yale Climate Change report [Marlon et al., 2020] shows that $64 \%$ of Americans, rarely or never discuss climate change, thus, eliciting curiosity and 
interest can be a strategy to encourage more conversations about the topic. Sjoberg's study [2007] addresses the topic of "interest" in wanting to learn more about the risk of certain phenomena and the willingness to engage in mitigating activities to reduce that risk. His results show a positive correlation between interest and risk perception of certain cases including terrorism but not regarding genetically modified food and mobile telephone use. The study shows a correlation between interest and expressed desire for risk mitigation. The author explains that perhaps, when individuals encounter a threatening situation, instead of suppressing the topic, they are willing to take action to mitigate the effects. He then calls for more research on "interest as a spontaneous reaction vs. interest as allocation of time and commitment (p. 233)."

With the lack of overwhelming research to show a connection between curiosity (or interest) and risk perception, researchers need to conduct more studies to examine such relationship. In addition, when the measurements focus on the participants' self-report of interest and curiosity, the outcomes are intentions and not behaviors. Thus, I will evaluate the relationship between curiosity and risk perception and risk mitigation (Figure 1), while measuring all curiosity and mitigation as behaviors rather than intentions. Curiosity in these hypotheses is the number of questions asked by the participants, leading to the following hypothesis:

H3: There is a positive relationship between curiosity in societal risk topics and risk perception.

H4: There is a positive relationship between curiosity in societal risk topics and risk mitigation behavior.

\section{Risk Perception, Warmth, and Trust}

While curiosity might be able to explain some of the variance in risk perception, trust could be another possible factor that account for changes in risk perception as well. One important factor influencing risk perception is trust in institutions and the competence of the source. Studies on trust in authorities who manage hazards [Flynn, Burns et al., 1992; Siegrist, 2000], government and businesses [Siegrist, 1999; Flynn, Slovic and Mertz, 1994], industry and the consumer's associations [Stefani et al., 2008], experts [Biel and Dahlstrand, 1995] and other institutes show that when one trusts the source, they perceive less threat from that institutions' product. Similarly, Grewal, Gotlieb and Marmorstein [1994] show that the source's higher credibility, defined as their trustworthiness and expertise, is correlated with lower risk perception of the product.

Researchers more frequently study the source attributes of trust and competence and not their warmth and friendliness. Fiske and Dupree [2014] suggest that trust in an individual is associated with how warm they are perceived as. Researchers frequently use these terms (warmth and trust) interchangeably [e.g., Cuddy, Glick and Beninger, 2011]. Communication scholars suggest that scientists should foster warmth to be trusted by the public. They see this as a potential remedy to public's refusal of facts and scientists' warnings. However, the proposed relationship might not be fully reflective of the public's thought-process. To have a better sense of their difference, I have included perception of warmth as a separate variable from trust 
in the model. Studies of Viklund [2003] and Sjöberg [2001] provide a possible explanation for the disconnect between trust and risk perception.

Sjöberg [2001] finds low correlation $(\mathrm{r}=0.3)$ between trust (defined as an individual's competence and care) and risk perception. He notes that the small effect of trust might be due to the public believing that there are limits to what experts and science knows. Similarly, Viklund [2003], through his analysis of multiple cross-cultural studies of trust has shown that trust's power to predict perception of risk differs amongst countries and depending on the risk itself. Additionally, measuring an individual's trust in the intention of a scientist could result in different outcomes compared to measuring an individual's trust in the scientist's behavior as it might affect an individual.

Measures such as that of Colquitt [2001] examines trust in a practical sense (i.e., relying on experts for decision-making). This measure of trust reflects reliance and willingness to be vulnerable. This could possibly eliminate the significant effect of trust on risk perception when the previous study results were an outcome of trusting the expert's intentions, rather than trust in their competence and the willingness to reply on them. Thus, in this study, instead of examining trust as an intention, I examine trust in scientist's reliability, as the participants' willingness to be vulnerable. In addition, the majority of the previous studies examine the effect of trust on the reduction of risk perception. In this study, I examine if trust can also increase risk perception (Figure 1).

Thus, I hypothesize the following:

H5: There is a positive relationship between trust in scientists' reliability and perception of risk about the harms of the topic they introduce.

The previous arguments highlight interesting gaps in the study of risk perception as it relates to trust in reliability and warmth. Although researchers at times use trust and warmth interchangeably, they have done a fair number of studies to investigate the effect of trust (perceiving positive intentions) in institutes on risk perception but have not studied warmth independently. Even though to my knowledge, there are no mentions of warmth in risk perception literature, some of these studies include elements of warmth in their evaluation of trust. For example, Kasperson, Golding and Tuler [1992] and Sjoberg's measure [2001] include caring, which is also present in the evaluation of warmth. Expanding on this measurement, I suggest that warmth could also produce effects similar to those of trust (Figure 1). Thus, I hypothesize:

H6: There is a positive relationship between the scientist's perceived warmth and perception of risk about the harms of the topic they introduce. 
To address these previous six hypotheses, I have conducted an online experiment on the Qualtrics platform. The intervention was in the form of an online post, read by the participants.

\section{Participants}

After a pilot run of 30 participants to determine the sample size, I have decided to recruit $385(18+)$ participants from the US for a power of 0.95 and an effect size of 0.26 through the Qualtrics online survey platform. They compensated each participant based on their company criteria. Qualtrics recruited participants based on a quota for an equal representation of political views, education, and gender.

\section{Measures}

In this section I will be describing different dependent and independent variables and how I measure them.

Warmth and competence perception. The Judd et al. [2005] measure of warmth evaluated based on a 0 (not at all) to 4 (extremely) scale is a simple tool to measure the perception of an individual's warmth. This measure examines an individual's perception of the subject's "sociability, warmth, friendliness, and caring" as their measure of warmth (Chronbach's $\alpha=0.89$ ). The final score was an accumulation of the four items $(M=14.11, S D=3.44)$. The Judd et al. measure also contains an evaluation of competence "motivated, intelligence, energy, and organization." I measured the perception of competence $(M=15.64, S D=3.23)$ caused by any of the four elements to make sure the effect is limited to increased warmth and no change in competence perception (Chronbach's $\alpha=0.87$ ).

Curiosity. As mentioned earlier, to acquire a measure of curiosity that reflects one's behavior rather than intention, I avoided using measures based on the participants' self-report. I instead used the participants' questions, and their willingness to be given more information as a behavioral measure of curiosity.

Researchers such as DuVall [2001] or Kowalski and Kowalski [2012], treat inquiry as a representation of curiosity, in addition, the study of Jirout [2011] shows a significant correlation between the level of curiosity and questions asked by participants.

Thus, in this study I used a behavioral measure of curiosity. This measure examines the intensity of participants' curiosity by asking the participants to list their questions. This method is in some ways similar to the thought-listing technique [Cacioppo, Hippel and Ernst, 1997] used to reach an individual's mental content (e.g., thoughts, images, ideas). In the thought-listing technique, individuals are asked to write down everything that comes to their mind at a specific time or regarding a specific topic. This method is also used to examine the intensity of one's elaboration about a topic [e.g., Frewer et al., 1997]. Similarly, using the prompt "please list any question you might have regarding the article" I am assessing the participants intensity of curiosity depending on the number of questions they ask. This measure as the number of questions asked, $(M=1.4, S D=$ 1.17) represents curiosity as a behavior. 
Risk perception. To measure risk perception, I have used the Industrial Strength Risk Perception Measure (ISRPM) developed by Kahan [2011] in which individuals are asked to evaluate the seriousness of a risk on 0-7 Likert scale. This measure used in different research has shown to be highly reliable. This measure will evaluate the participants' perception of the general risks of reduction in snowfall and river volumes, deforestation, ground sinking, and in general, climate change (Chronbach's $\alpha=0.89)$. The final measure is an accumulation of the 4 items $(M=$ 22.67, $S D=7.31)$.

Risk mitigation. Although there are self-report measures of risk mitigation [e.g., Sjöberg, 2007] to obtain a behavioral measure of the action, participants were asked to consider donating all or part of their compensation to a nonprofit active in climate change efforts. This measure is similar to that of Liu and Aaker [2008] asking individuals to donate a portion of a possible bonus payment in the study to "HopeBab". Using this measure, the authors examine "actual donation" as opposed to intention. Thus, I have examined the behavior to mitigate risk, I also examined the percentage of actual donation alongside risk perception $(M=12.24 \%$, $S D=25.02 \%$ ).

Trust in scientist's reliability. To measure trust in reliability, I used the Colquitt [2001] questionnaire. This measure particularly evaluates if the individual is willing to trust the scientists with practical tasks that influence them. This is done through questions such as trusting them with an important task without monitoring them, letting them take over an important issue and having control over one's future (rated 0-5). To calculate the final score, I accumulated five items related to trust in reliability $(M=13.44, S D=2.56)$ with a high Chronbach's $\alpha$ of 0.89 .

Covariates. Two measures were used as covariates: education and partisanship. Education, as shown before, seem to have significant effects on risk perception [Kahan et al., 2017; Newport and Dugan, 2015]. In addition, political partisanship seems to also determine an individual's risk perception [Renn and Rohrmann, 2000; Leiserowitz, 2006]. I measured both variables based on a categorical scale, from "less than high school graduate" to "graduate or professional degree" rated from one to seven $(M=4.46, S D=1.56)$ and from "extremely conservative" to "extremely liberal democrat" rated from one to five $(M=3.01, S D=1.41)$. I have also included the measure for need for cognition [Cacioppo, Petty and Kao, 1984]. This measure evaluates curiosity as an attribute rather than a state that can be elicited externally $(M=59.8, S D=11.31)$. It explores the individuals' willingness to think critically and appreciate complexity and is comprised of 18 items (Chronbach's $\alpha=0.83$ ).

\section{Procedure}

After completing the demographic information in addition to a need-for-cognition questionnaire, participants reported their identification with one of the political parties. Qualtrics then randomized participants into either the low personal anecdote disclosure or high personal anecdote disclosure $(n=204$ in low self-disclosure and $n=181$ in the high self-disclosure condition). The disproportionate number of participants in the two conditions is due to the data cleaning process. 
In this study, to operationalize self-disclosure through personal anecdotes, in the high disclosure condition, I have designed the manipulation based on a scientist disclosing more intimate and extensive personal information compared to the low-disclosure condition, similar to the manipulation used by Mazer and colleague's study design [2007].

Participants in the high disclosure of personal anecdote condition read news exert consisting of a small bio on a scientist's education (Dr. Mary Smith), followed by a section including a personal anecdote about the scientist's experience living near the mountains and how her family inspired her love of the environment. She includes her experience climbing the mountain with her dog, explaining her feelings and the scenery and her worry about the changing climate as it relates to her connection to the mountain. In the last section, the scientist talks about the negative effects of climate change. The low-disclosure condition uses the same scientific information but does not include any stories about the scientist's family, childhood, or personal activities. Instead, she talks about her education, her concern regarding scientific reports, and explaining the effects of climate change. I have written these scenarios loosely based on the World Wildlife Fund's Climate Witness Project [2008].

After reading the biography, participants were then asked to fill the warmth and competence questionnaire to determine their perception of the speaker's warmth and competence. Participants were then asked to list questions about the content of the material and write the number of questions they asked. Next, the audience was given a short questionnaire to measure their climate change risk perception followed by an offer to donate a portion of their compensation to a fictional nonprofit "Act Against Climate Change" for risk mitigation. Finally, the participants were provided with a questionnaire to evaluate their trust in scientist's reliability.

\section{Analysis}

I analyzed the results through structural equation modeling (SEM), treating disclosure of personal anecdotes, trust in the reliability, need for cognition, education, and partisanship as exogenous factors and warmth, competence, curiosity, risk perception and risk mitigation as endogenous factors. Education and partisanship are the covariates influencing risk perception and risk mitigation (Figure 2). I used R software's Lavaan package for this analysis.

When reporting this data, I will not use the Chi square to judge the fitness of the model. According to Kyriazos [2018], based on the work of Gatignon [2010] and Singh, Junnarkar and Kaur [2016] Chi square is extremely sensitive to the sample size. Thus, the test might fail to reject an unfit model in small sample sizes while it might falsely reject a model with good fit in a large sample size. The same paper suggests that based on a study by Curran et al. [2002] with sample sizes of more than 200, and in a model with moderate misspecification, RMSEA was an accurate indicator of fit. Thus, in this study, to examine the fit of the model instead of reporting Chi square, I mainly rely on the RMSEA indicator, followed by GFI, AGFI, and CFI. Based on the Schreiber et al. [2006] in this model, a good fit is indicated by the RMSEA <.06 to .08, AGFI, GFI and CFI above 0.95 and finally a lower $X^{2} / d f$ ratio also indicates a better fit, recommended below 2 or 3 . 
The t-test analysis for the effect of self-disclosure on curiosity shows no significant difference between low self-disclosure $(M=1.39, S D=1.13)$ and high self-disclosure group $(M=41, S D=1.21)$ conditions; $t(370.17)=-0.23024, p=0.81$. The main purpose of the manipulation was to produce two conditions with separate levels of induced-curiosity to examine if curiosity can cause increased risk perception and mitigation. However, since the manipulation did not cause such an effect, I will interpret all following outcomes as correlations.

\section{Tests of baseline conceptual model}

The SEM analysis of the baseline model shows the $X^{2} / d f$ ratio of 25.09 , highly above the suggested ratio of 3 shows the weak fit of the model, along the GFI, AGFI, and CFI below the 0.9 conventional criterion. However, the RMSA of $<0.00$ is below the 0.06 conventional criterion, indicating a good fit. Collectively, these indicators show a low fit of the baseline model (Table 1).

\section{Model Revision and Tests}

To address the low fit of the baseline model, I have used a modification test, examining what suggested changes can improve the model to the point of good fit to observed data. I have run four modifications and the final modification includes a GFI and CFI above the conventional criterion, as the AGFI of 0.89 is marginally below the 0.9 conventional criterion. As the RMSEA is below the conventional criterion and the $\mathrm{X}^{2} / d f$ ratio of 2.60 has been improved compared to the previous modification, I will consider the model as one with a generally good fit. The changes in chi square between models also shows an improvement in the model's ability to explain the variance in each of the dependent variables. The details of each modification are included in Tables 1 and 2.

Table 1. Summary of fit indices.

\begin{tabular}{|l|rccccccc|}
\hline Models & $X^{2}$ & $d f$ & $p$ & $X^{2} / d f$ & RMSEA & GFI & AGFI & CFI \\
\hline User model & 451.66 & 18 & 0.000 & 25.09 & 0.000 & 0.71 & 0.11 & 0.41 \\
Revised model 1 & 168.27 & 17 & 0.000 & 9.34 & 0.000 & 0.87 & 0.59 & 0.79 \\
Revised model 2 & 119.78 & 22 & 0.000 & 5.44 & 0.000 & 0.91 & 0.79 & 0.87 \\
Revised model 3 & 95.59 & 21 & 0.000 & 4.55 & 0.000 & 0.93 & 0.81 & 0.90 \\
Revised model 4 & 49.56 & 19 & 0.000 & 2.60 & 0.000 & 0.96 & 0.89 & 0.96 \\
\hline
\end{tabular}

Table 2. Summary of R squared for dependent variables in each model.

\begin{tabular}{|l|ccccc|}
\hline DV & Base model & Model 1 & Model 2 & Model 3 & Model 4 \\
\hline Warmth & 0.006 & 0.008 & 0.006 & 0.006 & 0.08 \\
Competence & 0.000 & 0.000 & 0.001 & 0.001 & 0.11 \\
Questions & 0.04 & 0.04 & 0.04 & 0.04 & 0.05 \\
Risk perception & 0.36 & 0.37 & 0.39 & 0.41 & 0.47 \\
Risk mitigation & 0.05 & 0.06 & 0.06 & 0.06 & 0.06 \\
Trust & - & - & 0.25 & 0.25 & 0.25 \\
\hline
\end{tabular}


Table 3 shows the summary of results from the final model. In this section, I will go through the results based on the study's hypotheses:

H1: Results show that the manipulation to elicit curiosity through self-disclosure does not have any significant effect $(\beta=0.03, p=0.77)$ and there was no difference between the low and high self-disclosure groups. Self-disclosure also had no significant effect on the perception of the scientist's warmth or competence.

H2: As the results show the significant effect of perception of warmth on the number of questions $(\beta=0.04, p=004)$, the data is consistent with the second hypothesis. However, since I have rejected the first hypothesis, showing the manipulation did not have an effect, I cannot establish a causal relationship between warmth and curiosity, but would rather state that there is a significantly positive relationship between scientist's warmth perception and the participants' number of questions. Additionally, there is a significant correlation between number of questions and need for cognition $(\beta=0.017, p=0.001)$.

H3: Risk perception is significantly correlated with the number of questions ( $\beta=$ $0.90, p=0.003)$. So, I will accept the second hypothesis.

H4: Unlike risk perception, risk mitigation is not significantly correlated with curiosity $(\beta=-0.04, \mathrm{p}=0.61)$, thus, rejecting the fourth hypothesis. Risk mitigation is only significantly correlated with political partisanship $(\beta=0.272, p<0.001)$.

H5: In line with this hypothesis, risk perception is significantly and positively correlated with trust in scientist's reliability $(\beta=0.52, p<0.001)$. In addition, risk perception is positively correlated with political partisanship $(\beta=2.56, p<0.001)$, and perception of scientist's competence $(\beta=0.47, p<0.001)$. These findings show that higher trust in scientist's reliability, perceiving them as more competence, and being more liberal positively correlates with perceiving the dangers of climate change.

H6: The results show no significant relationship between warmth perception and climate change risk perception $(\beta=0.23, p=0.7)$, so I reject the final hypothesis.

In addition to these results related to the study's hypotheses, the analysis showed that perception of trust is significantly correlated with perception of warmth ( $\beta=$ $0.172, p<0.001)$, and competence $(\beta=02.244, p<0.001)$ and warmth and competence are significantly correlated with one another $(\beta=6.975, p<0.001)$. Both perceptions of warmth and competence are significantly correlated by individual's political partisanship ( $\beta=0.681, p<0.001$ and $\beta=0.754, p<0.001$, respectively). These relationships are also depicted in Figure 3. 
Table 3. Summary of regressions, covariances and variances from the final model.

\begin{tabular}{|c|c|c|c|c|}
\hline Regressions & Estimate & Std. Err & z-value & $P(>|z|)$ \\
\hline Warmth $\sim$ self-disclosure & 0.47 & 0.33 & 1.42 & 0.15 \\
\hline Competence $\sim$ self-disclosure & -0.28 & 0.31 & -0.92 & 0.35 \\
\hline Questions self-disclosure & 0.03 & 0.11 & 0.28 & 0.77 \\
\hline Questions Warmth & 0.04 & 0.01 & 2.84 & $0.004^{*}$ \\
\hline Questions Need For Cognition & 0.01 & 0.005 & 3.42 & $0.001 *$ \\
\hline Risk Perception $\sim$ Political view & 2.56 & 0.2 & 12.84 & 0.000 * \\
\hline Risk Perception $\sim$ Education & -0.08 & 0.17 & -0.47 & 0.63 \\
\hline Risk Perception $\sim$ Trust & 0.52 & 0.11 & 4.42 & $0.000 *$ \\
\hline Risk Perception $\sim$ Competence & 0.47 & 0.09 & 4.92 & $0.000 *$ \\
\hline Risk Mitigation $\sim$ Political view & 0.27 & 0.05 & 4.94 & $0.000 *$ \\
\hline Risk Mitigation $\sim$ Education & 0.01 & 0.05 & 0.25 & 0.8 \\
\hline Trust $\sim$ Competence & 0.24 & 0.05 & 4.85 & $0.000 *$ \\
\hline Trust $\sim$ Warmth & 0.17 & 0.04 & 3.64 & $0.000 *$ \\
\hline Warmth $\sim$ Political view & 0.68 & 0.11 & 5.73 & $0.000 *$ \\
\hline Competence $\sim$ Political view & 0.75 & 0.11 & 6.86 & $0.000 *$ \\
\hline \multicolumn{5}{|l|}{ Covariance } \\
\hline Warmth $\sim \sim$ Risk Perception & 0.23 & 0.63 & 0.37 & 0.7 \\
\hline Questions Risk Perception & 0.9 & 0.3 & 2.93 & $0.003 *$ \\
\hline Questions Risk Mitigation & -0.04 & 0.08 & -0.49 & 0.61 \\
\hline Risk Perception $\sim \sim$ Risk Mitigation & 0.78 & 0.4 & 1.94 & 0.05 \\
\hline Warmth Competence & 6.97 & 0.62 & 11.2 & $0.000 *$ \\
\hline \multicolumn{5}{|l|}{ Variances } \\
\hline Warmth & 10.83 & 0.78 & 13.87 & 0.000 \\
\hline Competence & 9.27 & 0.66 & 13.87 & 0.000 \\
\hline Questions & 1.29 & 0.09 & 13.87 & 0.000 \\
\hline Risk perception & 27.51 & 1.98 & 13.87 & 0.000 \\
\hline Risk mitigation & 2.28 & 0.16 & 13.87 & 0.000 \\
\hline Trust & 4.9 & 0.35 & 13.87 & 0.000 \\
\hline
\end{tabular}

Discussion
The purpose of this study was to examine the relationship between scientist's features of warmth, competence, and trustworthiness with the number of questions asked by individuals as it relates to climate change, and how these factors affect the perception of risk of climate change and individual's actions to mitigate the risk. To elicit changes in the scientist's perception of warmth and competence and the number of questions asked by the participants, I have used scientist's self-disclosure manipulation. The results of this study show that scientist's self-disclosure as manipulated in the current study, does not significantly induce a higher number of questions. This could be due to a number of reasons, for one, this self-disclosure might have not been emotionally strong enough, lengthy enough, or revealing enough to elicit a reaction. Since the manipulation (self-disclosure) failed to invoke the desired effects, there is no distinction between the conditions, so I will not be able to make any causal inferences, and I will be describing all results as correlations rather than causations. 


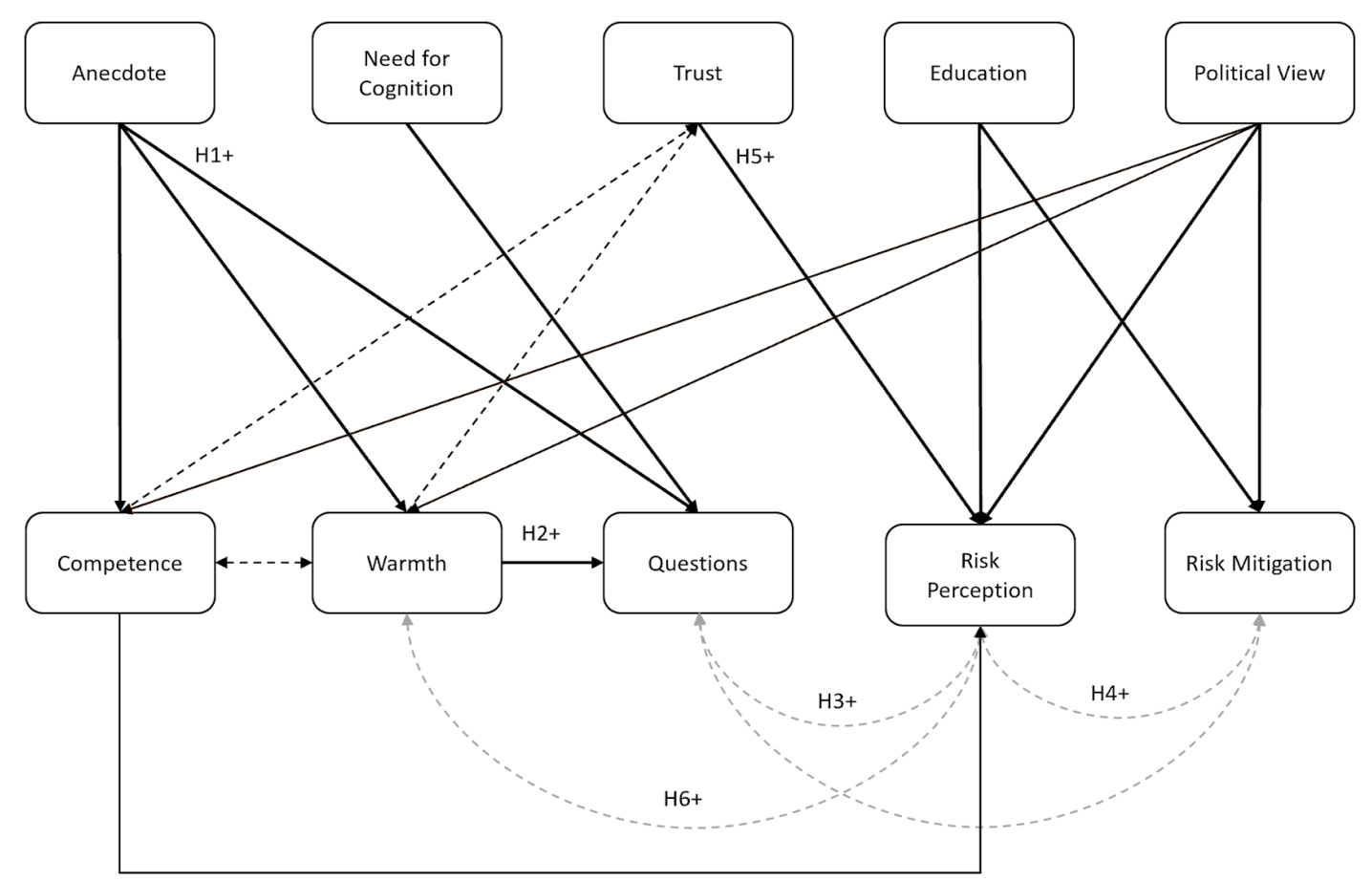

Figure 2. Final modified model for a Structural Equation Modeling analysis. NOTE: dashed lines represent correlational relationships.

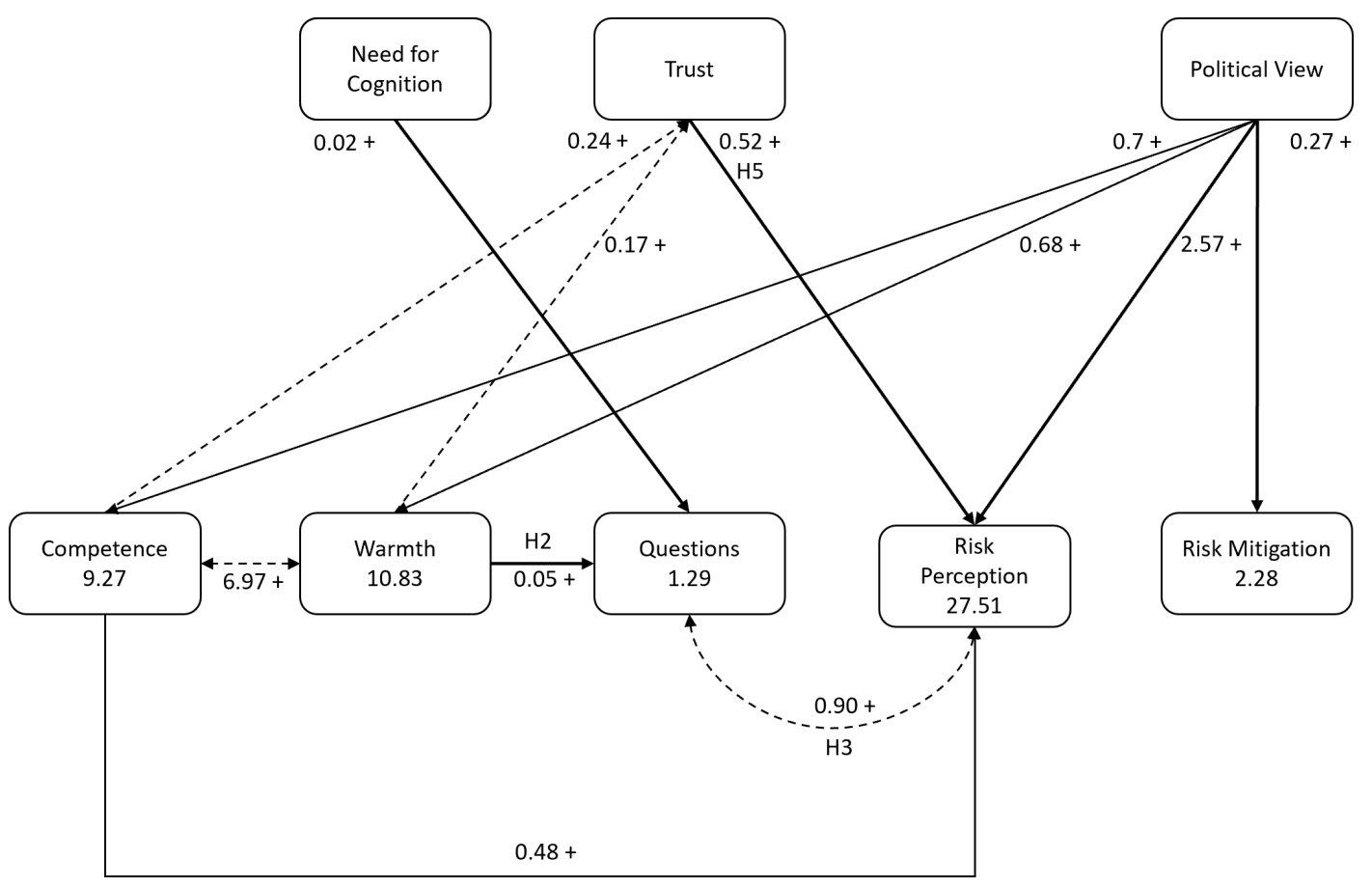

Figure 3. Final modified model for a Structural Equation Modeling analysis, only showing significant results. NOTE: dashed lines represent correlational relationships.

The studies on the effect of self-disclosure, mainly show the students' perception of participation in dialogue as, i.e., self-reports of being motivated to ask more questions or engage in more dialogues [e.g., Cayanus, Martin and Goodboy, 2009]. However, Wambach and Brothen [1997] have studied the behavior of student 
participation (i.e., if they ask more questions when the teacher engages in more self-disclosure). Their results, similar to the current study, show no significant change. As listing questions is a behavior, self-disclosure may affect perception of one's interest in asking more questions and being more cognitively engaged, rather than asking more questions. Another possible explanation could be that of the manipulation design and the weakness of the self-disclosure material to elicit effects shown in previous research. These findings point at the importance of measuring both intention and behavior when evaluating the effect of such manipulations. Besides, it highlights the need for more research on developing effective manipulations.

In line with the second hypothesis, the positive relationship between scientists' perceived warmth and higher number of questions affirms previous work on teacher warmth and student engagement [e.g., Hamre and Pianta, 2001; Hughes et al., 2008]. Most previous works have been evaluating engagement based on participants' self-reports. However, this study shows that warmth is positively correlated with engagement as curiosity behavior and not just intention and interests. In addition, the results expand the relationship beyond the teacher-student relationship to one between scientists and their audience.

The third hypothesis was aimed to examine if inducing curiosity, operationalized as asking more questions, will elicit higher risk perception to follow up on Kahan et al.'s [2017] study showing higher science curiosity is correlated with higher risk perception. Although due to the failed manipulation, the results cannot show the effect of induced curiosity, they do show a positive correlation.

However, the same relationship between curiosity and risk mitigation, as per hypothesis four, does not exist. This finding is counter to that of Sjöberg [2007]. Sjoberg examines if an individual's interest in a topic improves their report of risk mitigation activities. However, Sjoberg measures individual's reporting their intention to mitigate risks rather than their a ctual behavior. The current study demands real action on the spot (donating money) as a mitigation strategy. An important takeaway from the relationship between curiosity and risk perception and risk mitigation might be to emphasize on the practical effects of manipulations.

Results also confirm the fifth hypothesis, that the participants' trust in the scientist's reliability is positively correlated with perceiving the risk of climate change. This result builds upon previous studies that have been frequently examining how trust in a scientist can reduce the public's perception of risk of a threat [Flynn, Burns et al., 1992; Siegrist, 2000; Keller, Siegrist and Gutscher, 2006; Siegrist and Cvetkovich, 2000]. For example, if one trusts a company, they are more likely to perceive their products to be safe. This study shows that trust in a scientist's reliability is connected to accepting the scientist's views pro and against an issue, in this case, threats of climate change.

These results can also explain/complement Sjoberg's [2001] findings. Sjoberg shows a low correlation between trust and risk perception, attributing this to the way the public perceives scientist's limits, (i.e., scientist's might have good intentions but might not have all the knowledge needed to be trusted and be preceived as competent). This study's findings can shed light on this relationship by showing that if trust is defined as trust in scientist's reliability, then higher trust 
leads to higher risk perception, but the same is not necessarily true when trust represents believing a scientist has good intentions but not necessarily the competence to execute the right decision. This distinction can help future research to define trust as good intentions or as reliability, knowing that each might result in different outcomes.

Counter to trust, warmth did not significantly correlate to perception of the risk of climate change, as suggested in hypothesis six but competence was significantly correlated to risk perception. The significance of effect of trust can be possibly explained by scientist's competence rather than warmth. In other words, the participants might care more about the scientist's ability to make the right decisions rather than their positive intention (warmth). It seems like competence might play a more important role, with higher weight in determining trust in the scientist and perception of risk of climate change.

One of the most impactful variables in this model is the participants' political partisanship as a covariate. Individuals with conservative views show lower perception of risk of climate change, and risk mitigation behavior, lower perception of scientists' warmth, trust, and competence. These results are expected as also shown in different studies on the impact of political partisanship including Pew's latest report [Funk et al., 2019]. However, the second covariance, education, seems to have no significant effect on perception of risk. This outcome is also in line with Allum and colleagues' [2008] literature review showing that the relationship between general knowledge and attitude towards specific topics in science such a GMOs is not significant.

The main contribution of this research originates from the behavioral and practical measurements of the variables. As mentioned above, by evaluating risk mitigation and curiosity through behavioral measures, I provide additional evidence for how these variables act differently as intentions versus behaviors. Similarly, I measure trust as a more practical variable that signals reliability of scientists rather than their good intentions and provides results that are contrary to some previous work.

These results can contribute to how we value training scientists to become warmer, more trustworthy and signal competence and develop strategies to engage the public in dialogue. The outcomes also show the strength of pre-existing political views and how they are a powerful determinant of an individual's perceptions and actions. The power of this variable also suggests that many researchers and practitioners' communication strategies, including storytelling and self-disclosure might be limited by the audience's values, beliefs, and attitudes. This does not mean that communicators should not use these strategies, but that their effects might not be as strong as expected. Although this study and previous studies have not examined a causal relationship between curiosity and risk perception, there is a possibility for the effectiveness of this strategy in science communication practice, especially as it relates to controversial science topics.

\section{Limitations and future directions}

I have designed this study to examine different causal relationships between variables, however, due to the ineffectiveness of the manipulation, the outcomes 
show correlations rather than causations. Future researchers can design experiments with different manipulations to elicit specific effects, examining causal relationships between scientist's traits, public curiosity and risk perception and mitigation. In addition, the scientist in this study is a female climate scientist, not only a gender that faces more prejudice, but also an expertise that draws more controversy. While this agent can show certain aspects of science communication, it leaves out the comparison between different genders as the source and the effect of communicating less controversial science topics.

Future researchers should attempt to develop self-disclosure manipulations with stronger narratives that could elicit curiosity. The self-disclosure manipulation can also be stronger if placed in a more cohesive and transporting narrative [Green and Brock, 2000] where the reader feels the teller's emotions, is immersed in the story and is less aware of their surroundings. Also, manipulating different source attributes can provide valuable information about how different source attributes such as demographics, gender, and profession affect the message outcomes. The findings from this study are based on print messages in the form of interviews. Future research can also experiment with different message formats, including audio and video material.

\section{Conclusion}

The results of this study show that the manipulation to elicit warmth and curiosity by sharing different levels of disclosing personal anecdotes in the manner executed in this study does not make a significant impact. However, scientists' perceived warmth has a positive relationship with the number of questions participants asked about the topic, and this number is positively correlated with perceiving the risks of climate change. In addition, although warmth perception does not significantly affect risk perception, perception of scientist's competence and trust in their reliability have a positive relationship with risk perception. The results also show that affecting risk mitigation, as an act of donating money to climate change combating nonprofits might take more work compared to increasing risk perception.

I am hoping that the results of this study contribute to advocating for more dialogue and discussion about climate change and other controversial science topics to increase the public's perception of risk of climate change in addition to their mitigative behavior. Additionally, as a community of science communication researchers and communicators, we should explore ways to elicit curiosity about climate change and strategies to facilitate dialogue about this topic. This attempt can not only benefit the perception of science topics in society but is also a democratic way to build a participatory science environment.

Acknowledgments This study was a part of my dissertation project and I would like to thank my dissertation committee members for all their support and mentorship:

Dr. Michelle Shumate, Dr. Dan O'Keefe, Dr. John Besley, Dr. Dietram Scheufele, and Dr. Michael Horn. 
Aaker, D. A., Stayman, D. M. and Hagerty, M. R. (1986). 'Warmth in Advertising: Measurement, Impact, and Sequence Effects'. Journal of Consumer Research 12 (4), pp. 365-381.

Aaker, J., Vohs, K. D. and Mogilner, C. (2010). 'Nonprofits Are Seen as Warm and For-Profits as Competent: Firm Stereotypes Matter'. Journal of Consumer Research 37 (2), pp. 224-237. https: //doi.org/10.1086/651566.

Abrahamson, C. E. (2005). 'Motivating students through personal connections: Storytelling as pedagogy in Introductory Psychology'. In: Best practices for teaching introduction to psychology. Ed. by D. S. Dunn and S. L. Chew. Mahwah, NJ, U.S.A.: Erlbaum, pp. 245-258. https://doi.org/10.4324/9781410613431.

Allum, N., Sturgis, P., Tabourazi, D. and Brunton-Smith, I. (2008). 'Science knowledge and attitudes across cultures: a meta-analysis'. Public Understanding of Science 17 (1), pp. 35-54. https: //doi .org/10.1177/0963662506070159.

Altman, I. and Taylor, D. A. (1973). Social penetration: The development of interpersonal relationships. Holt, Rinehart \& Winston.

Arnone, M. P., Small, R. V., Chauncey, S. A. and McKenna, H. P. (2011). 'Curiosity, interest and engagement in technology-pervasive learning environments: a new research agenda'. Educational Technology Research and Development 59 (2), pp. 181-198. https://doi.org/10.1007/s11423-011-9190-9.

Biel, A. and Dahlstrand, U. (1995). 'Risk perception and the location of a repository for spent nuclear fuel'. Scandinavian Journal of Psychology 36 (1), pp. 25-36. https://doi.org/10.1111/j.1467-9450.1995.tb00965.x.

Cacioppo, J. T., Hippel, W. von and Ernst, J. M. (1997). 'Mapping cognitive structures and processes through verbal content: The thought-listing technique'. Journal of Consulting and Clinical Psychology 65 (6), pp. 928-940. https://doi.org/10.1037/0022-006x.65.6.928.

Cacioppo, J. T., Petty, R. E. and Kao, C. F. (1984). 'The Efficient Assessment of Need for Cognition'. Journal of personality assessment 48 (3), pp. 306-307. https://doi.org/10.1207/s15327752jpa4803_13.

Cayanus, J. L., Martin, M. M. and Goodboy, A. K. (2009). 'The Relation Between Teacher Self-Disclosure and Student Motives to Communicate'. Communication Research Reports 26 (2), pp. 105-113. https://doi.org/10.1080/08824090902861523.

Collins, N. L. and Miller, L. C. (1994). 'Self-disclosure and liking: A meta-analytic review'. Psychological Bulletin 116 (3), pp. 457-475. https://doi.org/10.1037/0033-2909.116.3.457.

Colquitt, J. A. (2001). ‘On the dimensionality of organizational justice: A construct validation of a measure'. Journal of Applied Psychology 86 (3), pp. 386-400. https://doi.org/10.1037/0021-9010.86.3.386.

Cozby, P. C. (1972). 'Self-Disclosure, Reciprocity and Liking'. Sociometry 35 (1), p. 151. https://doi.org/10.2307/2786555.

Cuddy, A. J., Glick, P. and Beninger, A. (2011). 'The dynamics of warmth and competence judgments, and their outcomes in organizations'. Research in Organizational Behavior 31, pp. 73-98. https://doi.org/10.1016/j.riob.2011.10.004.

Curran, P. J., Bollen, K. A., Paxton, P., Kirby, J. and Chen, F. (2002). 'The Noncentral Chi-square Distribution in Misspecified Structural Equation Models: Finite Sample Results from a Monte Carlo Simulation'. Multivariate Behavioral Research 37 (1), pp. 1-36. https://doi.org/10.1207/s15327906mbr3701_01. 
Douglas, M. and Wildavsky, A. (1983). Risk and culture. Berkeley, CA, U.S.A.: University of California press.

DuVall, R. (2001). 'Inquiry in science: From curiosity to understanding'. Primary Voices K-6 10 (1), pp. 3-9.

Epstein, J. L. (1981). 'Patterns of classroom participation, student attitudes, and achievements'. In: The Quality of School Life. Ed. by J. L. Epstein. Lexington, MA, U.S.A.: Lexington Books, pp. 81-115.

Fiske, S. T. and Dupree, C. (2014). 'Gaining trust as well as respect in communicating to motivated audiences about science topics'. Proceedings of the National Academy of Sciences 111 (Supplement 4), pp. 13593-13597. https://doi.org/10.1073/pnas.1317505111.

Fiske, S. T., Cuddy, A. J. C., Glick, P. and Xu, J. (2018). 'A model of (often mixed) stereotype content: Competence and warmth respectively follow from perceived status and competition'. In: Social Cognition. Ed. by S. T. Fiske. U.S.A.: Routledge, pp. 162-214. https://doi .org/10.4324/9781315187280.

Fiske, S. T., Xu, J., Cuddy, A. C. and Glick, P. (1999). '(Dis)respecting versus (Dis)liking: Status and Interdependence Predict Ambivalent Stereotypes of Competence and Warmth'. Journal of Social Issues 55 (3), pp. 473-489. https://doi.org/10.1111/0022-4537.00128.

Flynn, J., Burns, W., Mertz, C. K. and Slovic, P. (1992). 'Trust as a determinant of opposition to a high-level radioactive waste repository: Analysis of a structural model'. Risk analysis 12 (3), pp. 417-429.

Flynn, J., Slovic, P. and Mertz, C. K. (1994). 'Gender, Race, and Perception of Environmental Health Risks'. Risk analysis 14 (6), pp. 1101-1108. https://doi.org/10.1111/j.1539-6924.1994.tb00082.x.

Fredricks, J. A., Blumenfeld, P. C. and Paris, A. H. (2004). 'School Engagement: Potential of the Concept, State of the Evidence'. Review of Educational Research 74 (1), pp. 59-109. https://doi.org/10.3102/00346543074001059.

Frewer, L. J., Howard, C., Hedderley, D. and Shepherd, R. (1997). 'The Elaboration Likelihood Model and Communication About Food Risks'. Risk Analysis 17 (6), pp. 759-770. https://doi.org/10.1111/j.1539-6924.1997.tb01281.x.

Funk, C., Hefferon, M., Kennedy, B. and Johnson, C. (2nd August 2019). 'Trust and Mistrust in Americans' Views of Scientific Experts'. Pew Research Center. URL: https://www . pewresearch .org/science/2019/08/02/trust-and-mistru st-in-americans-views-of-scientific-experts/ (visited on 29th August 2019).

Gatignon, H. (2010). ‘Confirmatory Factor Analysis'. In: Statistical Analysis of Management Data. Springer New York, pp. 59-122. https://doi.org/10.1007/978-1-4419-1270-1_4.

Getahun, D., Aulls, M. and Saroyan, A. (2014). 'The nature of undergraduate students' conceptions of inquiry'. Electronic Journal of Science Education 18, pp. 1-24.

Gheorghiu, A. I., Callan, M. J. and Skylark, W. J. (2017). 'Facial appearance affects science communication'. Proceedings of the National Academy of Sciences 114 (23), pp. 5970-5975. https://doi.org/10.1073/pnas.1620542114.

Goldstein, G. S. and Benassi, V. A. (1994). 'The Relation between Teacher Self-Disclosure and Student Classroom Participation'. Teaching of Psychology 21 (4), pp. 212-217. https://doi.org/10.1207/s15328023top2104_2.

Golman, R., Loewenstein, G., Molnar, A. and Saccardo, S. (2012). The Demand for, and Avoidance of, Information. https ://doi .org/10.2139/ssrn. 2149362. 
Green, M. C. and Brock, T. C. (2000). 'The role of transportation in the persuasiveness of public narratives'. Journal of Personality and Social Psychology 79 (5), pp. 701-721. https://doi .org/10.1037/0022-3514.79.5.701.

Grewal, D., Gotlieb, J. and Marmorstein, H. (1994). 'The Moderating Effects of Message Framing and Source Credibility on the Price-Perceived Risk Relationship'. Journal of Consumer Research 21 (1), p. 145. https://doi.org/10.1086/209388.

Hamre, B. K. and Pianta, R. C. (2001). 'Early Teacher-Child Relationships and the Trajectory of Children's School Outcomes through Eighth Grade'. Child Development 72 (2), pp. 625-638. https://doi .org/10.1111/1467-8624.00301.

Hughes, J. N., Luo, W., Kwok, O.-M. and Loyd, L. K. (2008). 'Teacher-student support, effortful engagement, and achievement: A 3-year longitudinal study'. Journal of Educational Psychology 100 (1), pp. 1-14. https://doi.org/10.1037/0022-0663.100.1.1.

Hunt, J. M. V. (1965). 'Intrinsic motivation and its role in psychological development'. In: Nebraska symposium on motivation. Ed. by D. Levine. Vol. 13. Lincoln, NE, U.S.A.: University of Nebraska Press, pp. 189-282.

James, W. (1983). Talks to Teachers on Psychology and to Students on Some of Life's Ideals (Vol. 12). Cambridge, MA, U.S.A.: Harvard University Press.

Jepma, M., Verdonschot, R. G., Steenbergen, H. van, Rombouts, S. A. R. B. and Nieuwenhuis, S. (2012). 'Neural mechanisms underlying the induction and relief of perceptual curiosity'. Frontiers in Behavioral Neuroscience 6, 5. https://doi.org/10.3389/fnbeh.2012.00005.

Jirout, J. J. (3rd November 2011). 'Curiosity and the Development of Question Generation Skills'. In: AAAI fall symposium: Question generation. Pittsburgh, PA, U.S.A.: AAAI Publications.

URL: http://www . aaai.org/ocs/index.php/FSS/FSS11/paper/view/4194.

Judd, C. M., James-Hawkins, L., Yzerbyt, V. and Kashima, Y. (2005). 'Fundamental dimensions of social judgment: Understanding the relations between judgments of competence and warmth'. Journal of Personality and Social Psychology 89 (6), pp. 899-913. https://doi.org/10.1037/0022-3514.89.6.899.

Kahan, D. M. (2011). 'Fixing the Communications Failure'. Nature 463, pp. 296-297.

- (2016). Evidence-Based Science Filmmaking Initiative: Study No. 1. https://doi.org/10.2139/ssrn. 2713563.

Kahan, D. M., Landrum, A., Carpenter, K., Helft, L. and Jamieson, K. H. (2017). 'Science Curiosity and Political Information Processing'. Political Psychology 38, pp. 179-199. https://doi .org/10.1111/pops. 12396.

Kang, M. J., Hsu, M., Krajbich, I. M., Loewenstein, G., McClure, S. M., Wang, J. T.-y. and Camerer, C. F. (2009). 'The Wick in the Candle of Learning'. Psychological Science 20 (8), pp. 963-973. https://doi.org/10.1111/j.1467-9280.2009.02402.x.

Kashdan, T. B., Stiksma, M. C., Disabato, D. J., McKnight, P. E., Bekier, J., Kaji, J. and Lazarus, R. (2018). 'The five-dimensional curiosity scale: Capturing the bandwidth of curiosity and identifying four unique subgroups of curious people'. Journal of Research in Personality 73, pp. 130-149. https://doi.org/10.1016/j.jrp.2017.11.011.

Kasperson, R. E., Golding, D. and Tuler, S. (1992). 'Social Distrust as a Factor in Siting Hazardous Facilities and Communicating Risks'. Journal of Social Issues 48 (4), pp. 161-187. https://doi.org/10.1111/j.1540-4560.1992.tb01950.x. 
Keller, C., Siegrist, M. and Gutscher, H. (2006). 'The Role of the Affect and Availability Heuristics in Risk Communication'. Risk Analysis 26 (3), pp. 631-639. https://doi.org/10.1111/j.1539-6924.2006.00773.x.

Kowalski, F. V. and Kowalski, S. E. (2012). 'Enhancing curiosity using interactive simulations combined with real-time formative assessment facilitated by open-format questions on Tablet computers'. In: https://doi.org/10.1109/fie.2012.6462282.

Kyriazos, T. A. (2018). 'Applied Psychometrics: Sample Size and Sample Power Considerations in Factor Analysis (EFA, CFA) and SEM in General'. Psychology 09 (08), pp. 2207-2230. https://doi .org/10.4236/psych.2018.98126.

Lakoff, R. (1977). 'What you can do with words: Politeness, pragmatics and performatives'. Proceedings of the Texas conference on performatives, presuppositions and implicatures, pp. 79-106.

Landrum, A. R., Mills, C. M. and Johnston, A. M. (2013). 'When do children trust the expert? Benevolence information influences children's trust more than expertise'. Developmental Science 16 (4), pp. 622-638. https://doi.org/10.1111/desc.12059.

Leiserowitz, A. (2006). 'Climate Change Risk Perception and Policy Preferences: The Role of Affect, Imagery, and Values'. Climatic Change 77 (1-2), pp. 45-72. https://doi.org/10.1007/s10584-006-9059-9.

Liu, W. and Aaker, J. (2008). 'The Happiness of Giving: The Time-Ask Effect'. Journal of consumer research 35 (3), pp. 543-557. https://doi.org/10.1086/588699.

Loewenstein, G. (1994). ‘The psychology of curiosity: A review and reinterpretation'. Psychological Bulletin 116 (1), pp. 75-98. https://doi.org/10.1037/0033-2909.116.1.75.

Marlon, J., Howe, P., Mildenberger, M., Leiserowitz, A. and Wang, X. (2nd September 2020). 'Yale Climate Opinion Maps 2020'. Yale Program on Climate Chane Communication. URL: https://climatecommunication. yale. edu /visualizations-data/ycom-us/.

Mazer, J. P., Murphy, R. E. and Simonds, C. J. (2007). 'I'll See You On "Facebook": The Effects of Computer-Mediated Teacher Self-Disclosure on Student Motivation, Affective Learning, and Classroom Climate'. Communication Education 56 (1), pp. 1-17. https://doi.org/10.1080/03634520601009710.

Moreland, R. L. and Zajonc, R. B. (1982). 'Exposure effects in person perception: Familiarity, similarity, and attraction'. Journal of Experimental Social Psychology 18 (5), pp. 395-415. https: //doi .org/10.1016/0022-1031(82)90062-2.

National Academies of Sciences, Engineering and Medicine (2017). Communicating science effectively: a research agenda.

URL: https: //www . nap. edu/read/23674/chapter/1.

Newport, F. and Dugan, A. (26th March 2015). 'College-educated Republicans Most Skeptical of Global Warming'. Gallup News.

URL: https://news.gallup.com/poll/182159/college-educated-republican s-skeptical-global-warming. aspx.

Peeters, G. (1995). 'What's negative about hatred and positive about love? On negation in cognition, affect, and behavior'. In: Perspectives on negation. Ed. by H. C. M. de Swart and L. J. M. Bergman. Tilburg, the Netherlands: Tilburg University Press, pp. 123-133.

Peloza, J. and Hassay, D. N. (2006). 'Intra-organizational Volunteerism: Good Soldiers, Good Deeds and Good Politics'. Journal of Business Ethics 64 (4), pp.357-379. https://doi.org/10.1007/s10551-005-5496-z. 
Renn, O. and Rohrmann, B. (2000). 'Cross-Cultural Risk Perception: State and Challenges'. In: Cross-Cultural Risk Perception. Ed. by O. Renn and B. Rohrmann. Boston, MA, U.S.A.: Springer US, pp. 211-233. https://doi.org/10.1007/978-1-4757-4891-8_6.

Schreiber, J. B., Nora, A., Stage, F. K., Barlow, E. A. and King, J. (2006). ‘Reporting Structural Equation Modeling and Confirmatory Factor Analysis Results: A Review'. Journal of educational research 99 (6), pp. 323-338. https://doi.org/10.3200/joer.99.6.323-338.

Siegrist, M. (1999). 'A Causal Model Explaining the Perception and Acceptance of Gene Technology1'. Journal of Applied Social Psychology 29 (10), pp. 2093-2106. https://doi.org/10.1111/j.1559-1816.1999.tb02297.x.

- (2000). 'The Influence of Trust and Perceptions of Risks and Benefits on the Acceptance of Gene Technology'. Risk Analysis 20 (2), pp. 195-204. https://doi.org/10.1111/0272-4332.202020.

Siegrist, M. and Cvetkovich, G. (2000). 'Perception of Hazards: The Role of Social Trust and Knowledge'. Risk Analysis 20 (5), pp. 713-720. https://doi.org/10.1111/0272-4332.205064.

Silvia, P. J. (2008). 'Interest-The Curious Emotion'. Current Directions in Psychological Science 17 (1), pp. 57-60. https://doi.org/10.1111/j.1467-8721.2008.00548.x.

Singh, K., Junnarkar, M. and Kaur, J. (2016). Measures of Positive Psychology. Springer India. https : / doi . org/10.1007/978-81-322-3631-3.

Sjöberg, L. (2000). 'Factors in Risk Perception'. Risk Analysis 20 (1), pp. 1-12. https://doi.org/10.1111/0272-4332.00001.

- (2001). 'Limits of Knowledge and the Limited Importance of Trust'. Risk Analysis 21 (1), pp. 189-198. https://doi .org/10.1111/0272-4332.211101.

- (2007). 'Emotions and Risk Perception'. Risk Management 9 (4), pp. 223-237.

Skinner, E. A. and Belmont, M. J. (1993). 'Motivation in the classroom: Reciprocal effects of teacher behavior and student engagement across the school year'. Journal of Educational Psychology 85 (4), pp. 571-581. https://doi.org/10.1037/0022-0663.85.4.571.

Skinner, E. A., Wellborn, J. G. and Connell, J. P. (1990). 'What it takes to do well in school and whether I've got it: A process model of perceived control and children's engagement and achievement in school'. Journal of Educational Psychology 82 (1), pp. 22-32. https: //doi.org/10.1037/0022-0663.82.1.22.

Sorensen, G. (1989). 'The relationships among teachers' self-disglosive statements, students' perceptions, and affective learning'. Communication Education 38 (3), pp. 259-276. https://doi .org/10.1080/03634528909378762.

Stefani, G., Cavicchi, A., Romano, D. and Lobb, A. E. (2008). 'Determinants of intention to purchase chicken in Italy: the role of consumer risk perception and trust in different information sources'. Agribusiness 24 (4), pp. 523-537. https://doi.org/10.1002/agr. 20177.

Viklund, M. J. (2003). 'Trust and Risk Perception in Western Europe: A Cross-National Study'. Risk Analysis 23 (4), pp. 727-738. https://doi.org/10.1111/1539-6924.00351.

Voelkl, K. E. (1995). 'School Warmth, Student Participation, and Achievement'. The Journal of Experimental Education 63 (2), pp. 127-138.

Wambach, C. and Brothen, T. (1997). 'Teacher Self-Disclosure and Student Classroom Participation Revisited'. Teaching of Psychology 24 (4), pp. 262-263. https://doi.org/10.1207/s15328023top2404_7. 
Wheeless, L. R. and Grotz, J. (1976). 'Conceptualization and measurement of reported self-disclosure'. Human Communication Research 2 (4), pp. 338-346. https://doi.org/10.1111/j.1468-2958.1976.tb00494.x.

World Wildlife Fund (30th May 2008). Climate Witness: Octavio Mancilla, Mexico. URL: http://www. wwf .org.co/?135481/1/ (visited on 2nd November 2018).

Zahry, N. R. and Besley, J. C. (2021). 'Can scientists communicate interpersonal warmth? Testing warmth messages in the context of science communication'. Journal of Applied Communication Research 49 (4), pp. 387-405. https://doi.org/10.1080/00909882.2021.1880017.

Author

Reyhaneh (Rey) Maktoufi has successfully defended her Ph.D. in Media, Technology, and Society at Northwestern University. She is a Rita Allen Foundation Civic Science Fellow at WGBH/NOVA. In her role as a misinformation fellow, she does research on science communication in science filmmaking and produces videos to communicate the science of science communication. She was a visiting researcher at the Adler Planetarium, where she studied science communication and facilitated workshops on communication skills and she's also a producer at The Story Collider podcast. Before starting a Ph.D., Rey has been working as a health communication facilitator and cancer preventive/palliative care campaign manager in Tehran, Iran. Rey currently enjoys working with different nonprofits such as the Communicating Science Conference (ComSciCon). She also engages in science outreach through writing blog-posts and making science comics and has been interviewed on outlets such as the Smithsonian Magazine and the SETI Institute's podcast Big Picture Science. E-mail: r.maktoufi@gmail.com.

\section{How to cite}

Maktoufi, R. (2021). 'Understanding the relationship between sharing personal anecdotes, warmth, curiosity, risk perception and mitigation in communicating the threat of climate change'. JCOM 20 (07), A08.

https://doi.org/10.22323/2.20070208. 